\title{
Wild Plants' Use Behaviour in Meru, Kenya
}

\author{
Alfreda Kajira Ibui \\ Department of Earth Sciences, National Museums of Kenya, Nairobi 00100, Kenya
}

\begin{abstract}
Ethnobotanical record derived from the interaction between the Meru people and their wild plants reveals a high degree of dependency on medicinal and non-medicinal uses of these plants. The dependency is punctuated by the availability of various plant species growing in the region which humans have interacted with for generations. Indeed environment favourable for equatorial forests where temperatures favour growth of various species of plants help to make this region a pharmacy in waiting. Five hundred and sixty seven plant specimens collected in three districts of the greater Meru region have been reported to be used to heal a wide range of diseases and also fulfil other non-medicinal needs as they provide food, fuel and materials among others. Data collected through structured interviews from respondents in the region reveal significant factors that play major roles in the lives of the people thus influencing their social and cultural behaviour.
\end{abstract}

Key words: Human, plants, interaction, medicinal, non-medicinal, use, behaviour, factors.

\section{Introduction}

The people of Meru, in Kenya, who are called the Meru, Ameru or Amiiru, live on the eastern slopes of Mount Kenya. The use of wild plants in this part of Africa is becoming increasingly visible in regard to medicine, food, material, social uses, construction, fuel, environmental beauty as well as wind and dust breaks. In particular, medicine from wild plants is beginning to compete with conventional medicines in the fight against diseases and ailments. They have been proven to provide health care in countries that include South Africa, Indonesia, and China, just to mention a few. In an earlier field expedition, 567 plants were collected, pressed and preserved. This paper discusses the interactions reported by the people in three villages in Meru North, Meru Central and Meru South districts during this field season. It lays special emphases on the use of plants both in medicine and other non-medicinal uses. This grouping was necessitated by the fact that $53.8 \%$ of all the plants collected were reported to be used for preparing medicine, while the rest $46.2 \%$ were used for other uses (food, social/cultural, fuel, material,

Corresponding author: Alfreda Kajira Ibui, Ph.D., research field: medical anthropology and ethnobotany. E-mail: aibui@museums.or.ke, aibui8@gmail.com. environmental, as bee plants and as insecticides). The surrounding environs of Meru that are much drier than Mount Kenya region equally report sustained use of wild plants especially for medicine.

\section{Study Area}

The study area in the greater Meru region shown in Fig. 1, centred on three villages in Meru North (Semi-urban), Meru Central (Urban) and Meru South (Rural) Districts, respectively. Meru North is characterised by the Nyambene Hills which determine the general landscape. There is a plateau that runs south to north from Mount Kenya to the hills. Temperatures range from $24.7^{\circ} \mathrm{C}$ to $13.7^{\circ} \mathrm{C}$. Rainfall is bi-annual and comes from March to May and October to December. It ranges between 1,250-2,514 $\mathrm{mm}$ on the windward side and 350-1,000 mm on the leeward.

Meru Central lies within latitude $0^{\circ} 3{ }^{\prime} 45^{\prime \prime} \mathrm{N}$ and $0^{\circ} 2^{\prime} 30^{\prime} \mathrm{S}$, and longitudes $37^{\circ}-38^{\circ}$ east. Mount Kenya and Imenti forests located in this district cover 1,030 $\mathrm{km}^{2}$. Mount Kenya, the second highest mountain in Africa, provides the greatest influence on the natural conditions in Meru as a whole [1]. The altitudes that range from 3,000-5,199 ft above sea level supports various types of vegetation that include bush land and 


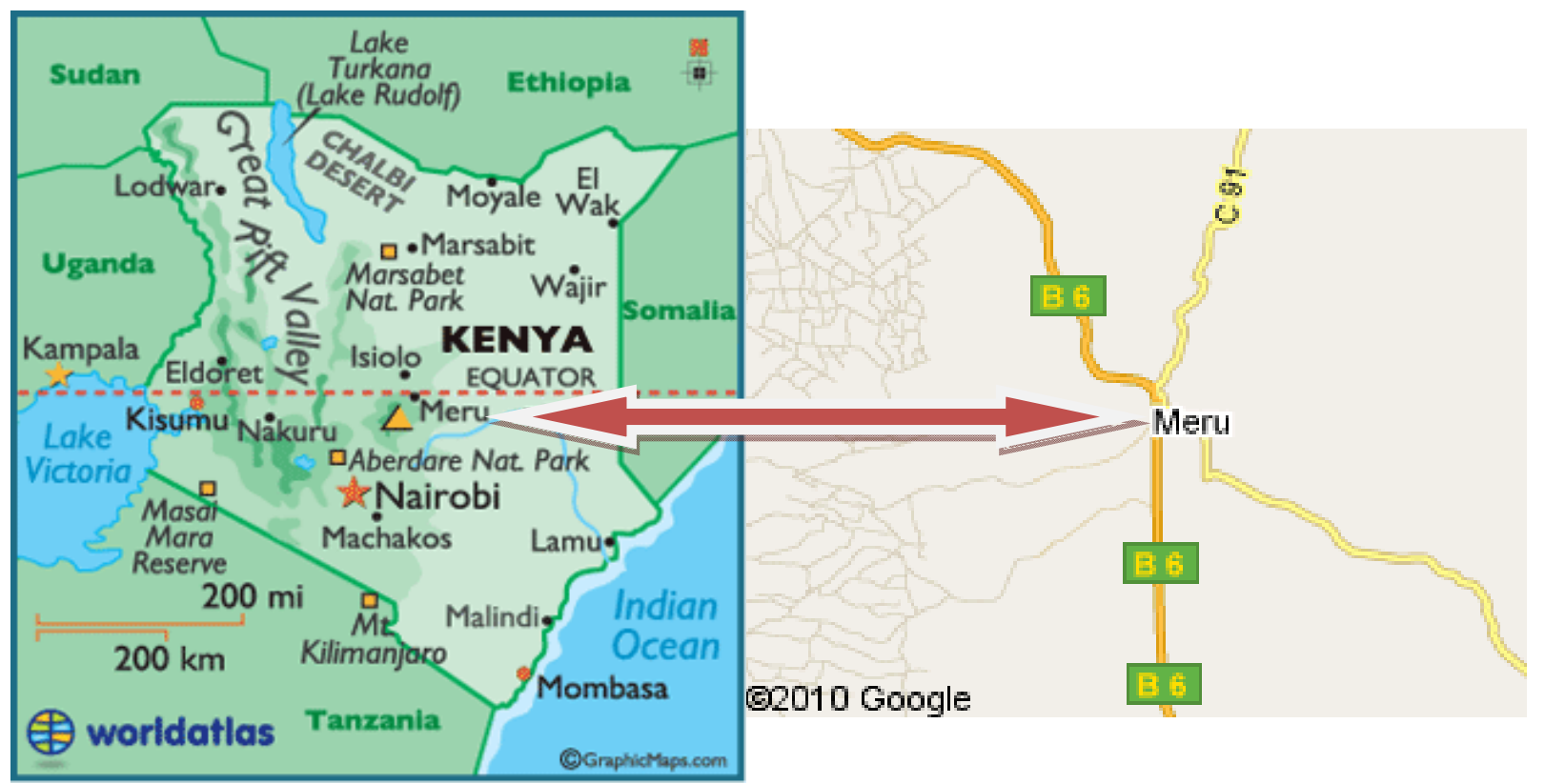

Fig. 1 Map of GraphicMaps showing the location of Meru.

thickets, dry woodland forest, mixed forest with star-grass, black mountain forest, bamboo and moor. Meru South District altitude ranges from $400 \mathrm{~m}$ to 5,200 m above sea level. Meru Central has a forest cover of $360 \mathrm{~km}^{2}$ which is part of Mount Kenya. Temperatures range from $14{ }^{\circ} \mathrm{C}$ to $17{ }^{\circ} \mathrm{C}$ on the highlands and $22{ }^{\circ} \mathrm{C}-27{ }^{\circ} \mathrm{C}$ in the lowlands. Mount Kenya forest is the source of the main rain that drains into the Indian Ocean through the Tana River. Rains range from $500 \mathrm{~mm}$ in lower areas to 2,200 mm towards the forest.

\section{Materials and Methods}

From the three villages, 567 plants specimens were collected, which are fairly a representative of the vegetation found in the region. The qualitative data comprised of 77 families, 178 genera and 271 species. Among these, 422 plants were reportedly used for medicinal purposes. The plants were preserved observing herbaria rules by pressing, drying, preserving and storing. Identification was done by botanists of the National Museums Kenya herbarium. The bulk of the data derived from the botanical study of the plants were later subjected to several analyses. Analyses of data were done by use of the Statistical
Program for Social Sciences (SPSS) version 12.5 $[2,3]$.

Quantitative data was collected by use of structured questionnaires. The respondents' use of wild plants in the year before the interview was recorded. In addition several factors were also recorded, which were seen to be most influential as far as the behavior of the People of Meru was concerned. These factors are given as follows:

Predisposing factors: (1) socio-demographic factors were the first category that included household size, sex, age, formal education, marital status and profession; while psycho-social factors included, knowledge of wild plants, knowledge of plants among children, belief in wild plants use, attitude towards wild plants use, awareness of plant environment, preparedness to pay for wild plants, perceived need of wild plant resources and experience in the use of wild plants. (2) The second category of factors considered were enabling factors that included, the respondent's socio-economic status analysed from, the type of house they lived in if stone, wooden or mud walled, type of roofing if thatched with plant leaves, corrugated iron sheets or bricks, number of sleeping rooms, ownership of rural and urban land. These are factors that define an 
individual's SES (social economic status) according to the Meru people. (3) The third set of factors taken into account were those relating to environment: environmental factors that included the three sites or villages where data was collected. (4) The fourth set were the conservation factors which were analysed depending on whether the respondents' cut trees (low conservation), cut trees and planted same number as those cut (average conservation), or just planted and did not cut any trees at all (high conservation) in the previous year. (5) Intervening factors including institution and governing policies that could have encouraged (encouraging policies) or discouraged (discouraging policies) the use of wild plants among the Meru, were the fifth set that were analysed. Behaviour was then observed by analysing the results of the two independent variables of medicinal and non-medicinal use.

\section{Results, Analysis and Discussion}

The data was subjected to a three step analysis that involved the bivariate, the multivariate and overalls, and the multiple regression analysis.

\subsection{The Bivariate Analyses}

The bivariate results shown in Fig. 2 revealed that the variable environment (villages) (Pearson Chi-Square 0.000), knowledge of medicinal plants use (Pearson Chi-Square 0.000), encouraging policies (Pearson Chi-Square 0.000), knowledge of non-medicinal plants use (Pearson Chi-Square 0.002), experience on non-medicinal plants use (Pearson Chi-Square 0.006), profession of household head (Pearson Chi-Square 0.007), formal education (Pearson Chi-Square 0.008), sex of household head (Pearson Chi-Square 0.008), and experience in medicinal wild plant use (Pearson Chi-Square 0.017) among the independent variables, and experience in wild medicinal plant use (Pearson Chi-Square 0.017), among the dependent variables exerted the highest influence on the peoples' medicinal plants use behaviour.

In relation to non-medicinal wild plants use behaviour, discouraging policies (Pearson Chi-Square 0.000), household size (Pearson Chi-Square 0.018), percieved need for wild plant resources (Pearson

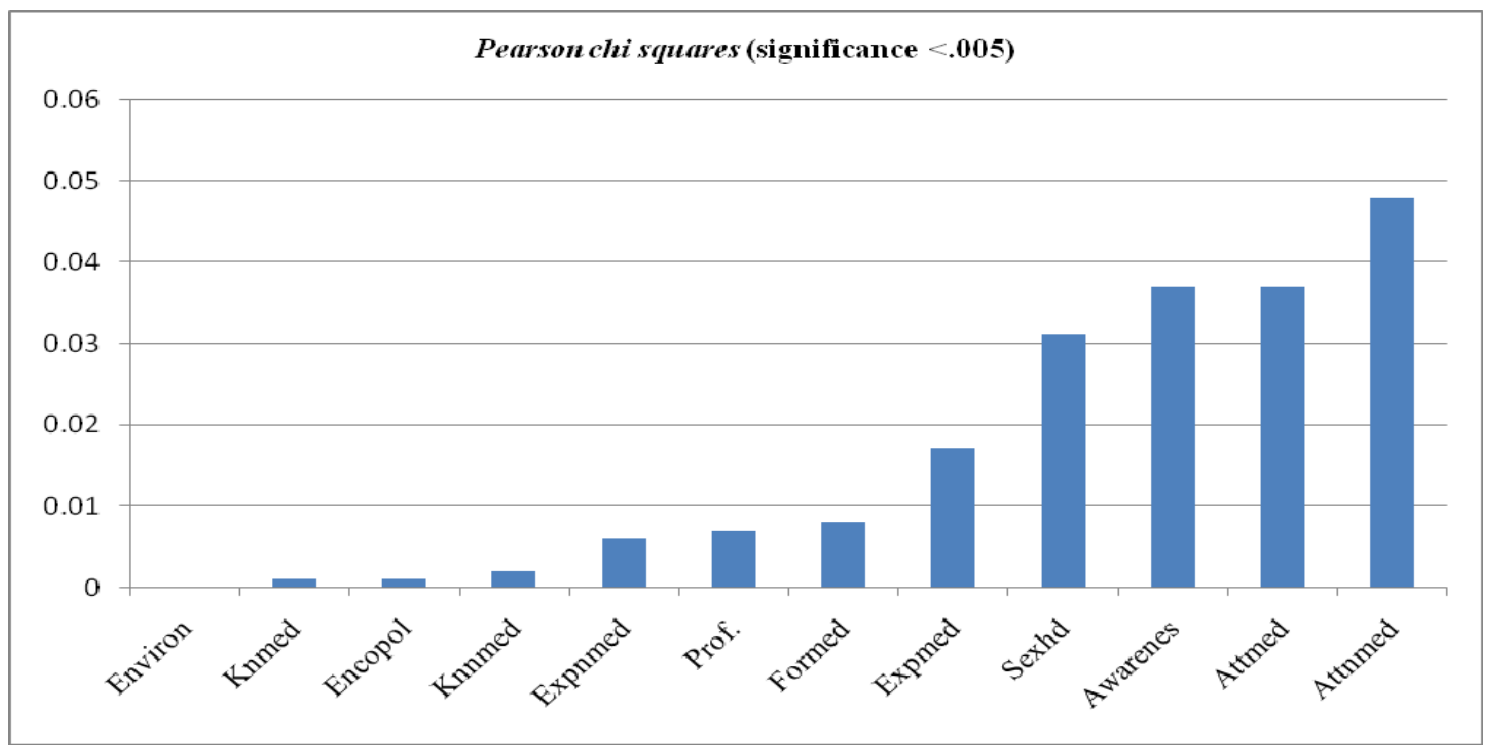

Fig. 2 Pearson Chi-Squares of various variables showing their varying influennce on wild medicinal plants use behavior. Pearson Chi-Squares showing the influence exerted by Environ (Environment), Knmed (Knowledge), Encopol (Encouranging policies), Knnmed (Knowledge in non-medicinal) Expnmed (Experience in non-medicinal), Prof (Profession), Formed (Formal education), Expmed (Experience in medicinal), Sexhd (Sex of Household head), Awarenes (Awarenes of plant environments), Attmed (Attitude in medicinal) and Attnmed (Attitude in non-medicnal) in wild medicinal plants use. 


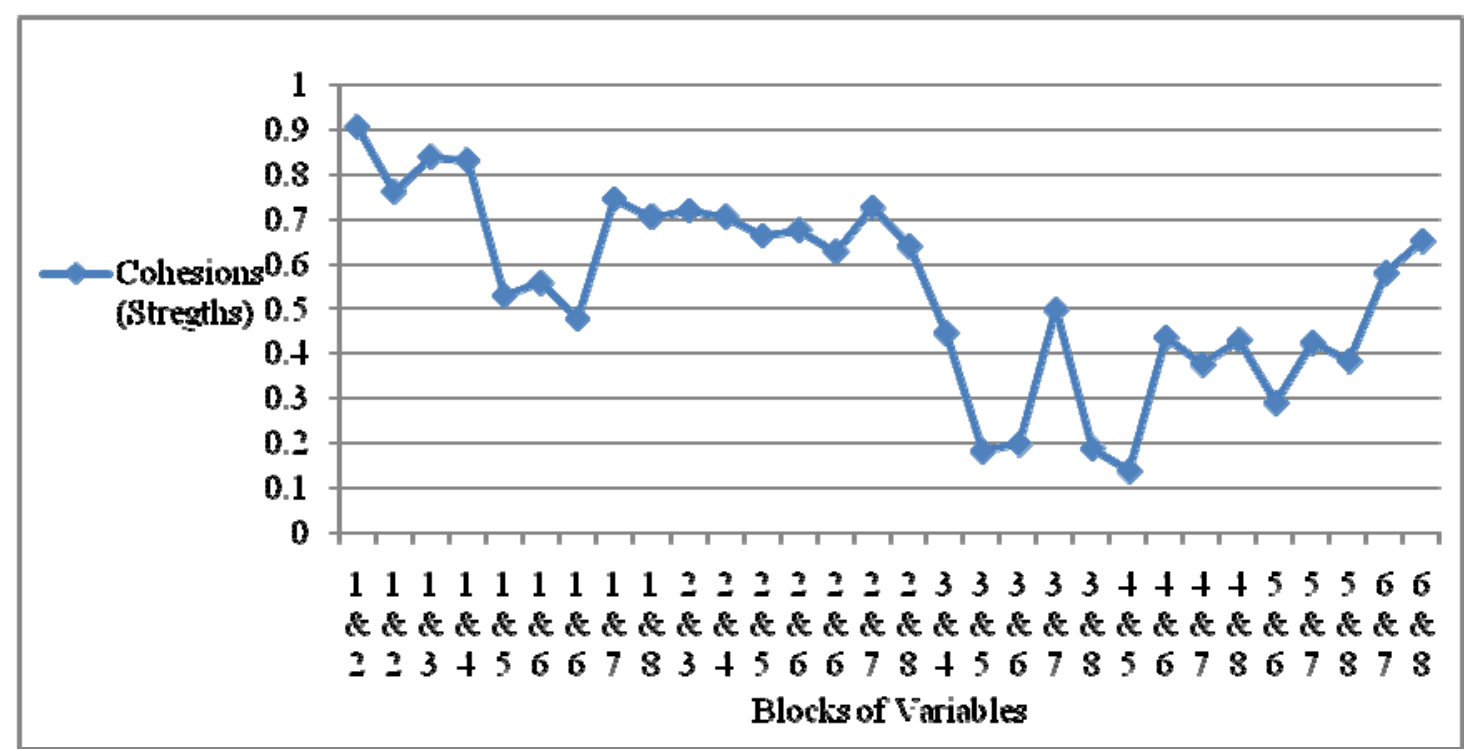

Fig. 3 Cohesion between the various blocks of variables.

Chi-Square 0.040) among the independent variables and, experience in non-medicinal wild plant use (Pearson Chi-Square 0.050) among the dependent variables exerted the highest influence.

\subsection{The Multivariate Analyses: OVERALS}

Multivariate and overals analyses confirmed the reults of the bivarite analyses where the OVERALS, through the distribution of component loadings showed that environment (component loadings 0.580) in dimension 1 and knowledge of medicinal plant use (component loadings 0.412 ) in dimension 1 were exerting the greatest influence in wild plants use behaviour, while sex of household head (component loadings 0.460 ) in the second dimension came out strongly, thus influencing wild plants use behaviour among the people of Meru.

\subsection{Multiple Regression Analysis}

Strength in cohesions between various blocks of variables was calculated by multiple correlation coefficient $(r)$, where $r=$ (2'Ed)-1 (Ed stands for Eigenvalue-a statistical term for values generated during the analyses) revealing that there exists strong coherences between the blocks of independent $(1=$ socio-demographic, 2 = psycho-social, 3 = enabling, 4
$=$ environmental, $5=$ conservation); intervenig $(6=$ policies) and dependent variables ( $7=$ medicinal and 8 = non-medicinal wild plants use) [2-4].

The blocks with the strongest coherences were those of predisposing and psycho-social variables as seen in blocks: $1 \& 2(r=0.906)$ in dimension1, $1 \& 3(r=$ $0.840)$ in dimension $1,1 \& 4(r=0.832)$ in dimension 1 , $1 \& 7(r=0.746)$ in dimension 1 and $1 \& 2(r=0.762)$ in dimension 2. Other blocks which showed relative strengths were $1 \& 7$ in dimension 1 ( $r=0.746), 2 \& 7$ $(r=0.726)$ in dimension $1,2 \& 3(r=0.720)$ in dimension 1 and $1 \& 8(r=0.706)$ in dimension 1 among others. All these revealed strong cohesion in relation to wild plants use in Meru, thus portraying their influence in wild plants use behaviour among the people as shown in Fig. 3 above.

When the cohesion existing between each block was calculated, it becomes possible to incorporate these strengths into an analytical model [2, 3].

\section{Conclusions}

The study revealed that wild plants play a key role in use behaviour among the people of Meru. In this behaviour, environment provided the greatest influencein medicinal and non-medicinal plants use. Knowledge of plants and sex of household head 
equally proved significant in wild plants use among the Meru. In addition, blocks of variables are seen to exert significant influence in the overall use of wild plants thus influencing wild plants use behaviour among the Meru. From the cohesions observed between blocks of variables in the model, there would be a definite change in lifestyle among the people of Meru that would cause visible instability if any of the factors changed. Above all, use of medicinal plants in Meru as a complement to primary health care is observed and recorded among the people. The great knowledge of the people relating to useful plants and their medical properties was reported to stretch back in time to several generations.

\section{Acknowledgments}

I am grateful to the experts who provided the wealth of information on wild plants use in Meru. These include, Kibara Francis Mwiandi, Kinankau Igweta, Martin Mwitu, Mathiu M’Rukwaru, M’Imunya M’Ibui, M'Rukaria M'Ikirima, Onesmus Mwiathi Mwirichia, Rebecca M’Ikunyua, Teratisio Mwenda Mwirabua, Winifred Kanyua Jaban, Andrew Kilemi Mugucia, Bretah Ciangai, Charles Kanampiu Mutirithia, M'Imathiu M’Imari, Eric Njue Nkiria, Evangeline Mwarania, Geoffrey M'Mugwika Mbogori, Godfrey Bariu, Henry Muriuki Muketha, Imathiu M’Rukwaru,
Irene Ciankuru Nyaga, Jacob M’Kaibi, John Murithi, Joseph Kaaria, Justus Karuga and Kanampiu Rimunya. I am also grateful for the great assistance I got in the field from Caroline Ntinyari Arimi, Daniel Mugaa Ibui, Fredrick Maingi Imanene, Irene Waithera Maina, Timothy Gichunge Ibui, Thomas Mboya Mwenda, Martha Karari, Samuel Murangiri Ibui and Onesmus Mwiathi Mwirichia. This research was supported by funds from the National Museums of Kenya, the Kenya Museum Society, and Leiden University in the Netherlands.

\section{References}

[1] Administrative geographic and physical description, Effective Management for Sustainable Economic Growth and Poverty Reduction: Report from the Meru Central District Development Plan 2002-2008.

[2] A.K. Ibui, Indigenous Knowledge, Belief and Practise of Wild Plants in Meru: Past and Present Human Plant-Relations in East Africa, VDM Verlag Dr. Müller Aktiengesellschraft \& Co. KG, Saabrucken, Germany, 2009, pp. 215-256 (Chapter 9).

[3] A.K. Ibui, Indigenous knowledge, Belief and Practice of Wild Plants among the Meru of Kenya: Past and Present Human-plant Relations in East Africa, Ph.D. Thesis, University of Leiden, C.D.P. Leiden, The Netherlands, 2007.

[4] E. Van der Burg, J. De Leeuw, Use of the Multinomial Jackknife and Bootstrap in Generalized Nonlinear Canonical Correlation Analysis, Applied Stochastic Models and Data Analysis 4 (3) (1988) 159-172. 